\title{
ARTICLE
}

Lymphoma

\section{Blood and skin-derived Sezary cells: differences in proliferation- index, activation of PI3K/AKT/mTORC1 pathway and its prognostic relevance}

\author{
Cristina Cristofoletti ${ }^{1}$ - Antonella Bresin ${ }^{1} \cdot$ Mario Picozza $^{2}$ - Maria Cristina Picchio ${ }^{1}$ Francesca Monzo ${ }^{1}$. \\ Mauro Helmer Citterich ${ }^{1}$ - Francesca Passarelli ${ }^{1}$ - Alessandra Frezzolini ${ }^{1} \cdot$ Enrico Scala $^{1} \cdot$ Alessandro Monopoli $^{1}$. \\ Maria Cantonetti ${ }^{3} \cdot$ Roberto Benucci $^{1} \cdot$ Stefania D'Atri ${ }^{1} \cdot$ Elisabetta Caprini ${ }^{1} \cdot$ Giandomenico Russo $^{1}$. \\ Maria Grazia Narducci ${ }^{1}$
}

Received: 27 June 2018 / Revised: 25 September 2018 / Accepted: 12 October 2018 / Published online: 5 December 2018

(c) The Author(s) 2018. This article is published with open access

\begin{abstract}
Sézary syndrome (SS) is a rare and aggressive variant of Cutaneous T-Cell Lymphoma characterized by neoplastic distribution mainly involving blood, skin, and lymph-node. Although a role of the skin microenvironment in SS pathogenesis has long been hypothesized, its function in vivo is poorly characterized. To deepen this aspect, here we compared skin to blood-derived SS cells concurrently obtained from SS patients highlighting a greater proliferation-index and a PI3K/AKT/mTORC1 pathway activation level, particularly of mTOR protein, in skin-derived-SS cells. We proved that SDF-1 and CCL21 chemokines, both overexpressed in SS tissues, induce mTORC1 signaling activation, cell proliferation and Ki67 up-regulation in a SS-derived cell line and primary-SS cells. In a cohort of 43 SS cases, we observed recurrent copy number variations (CNV) of members belonging to this cascade, namely: loss of LKB1 (48\%), PTEN (39\%) and PDCD4 $(35 \%)$ and gains of P70S6K (30\%). These alterations represent druggable targets unraveling new therapeutic treatments as metformin here evaluated in vitro. Moreover, CNV of PTEN, PDCD4, and P70S6K, evaluated individually or in combination, are associated with reduced survival of SS patients. These data shed light on effects in vivo of skin-SS cells interaction underlying the prognostic and therapeutic relevance of mTORC1 pathway in SS.
\end{abstract}

\section{Introduction}

Sézary syndrome (SS) is a rare aggressive leukemic variant of cutaneous T-cell lymphomas (CTCLs) in which malignant

Electronic supplementary material The online version of this article (https://doi.org/10.1038/s41375-018-0305-8) contains supplementary material, which is available to authorized users.

$\triangle$ Giandomenico Russo

g.russo@idi.it

$\triangle$ Maria Grazia Narducci narducci@idi.it

1 Istituto Dermopatico dell'Immacolata, IDI-IRCCS, 00167 Rome, Italy

2 Laboratory of Neuroimmunology, Fondazione Santa Lucia, 00143 Rome, Italy

3 Department of Hematology, University of Tor Vergata, 00133 Rome, Italy
T cells accumulate in the skin, lymph nodes and blood, typically resulting in a shortened life expectancy with a median of survival of 63 months [1,2].

SS cells express CD45R0 + CCR7 + CD27 + CD62L + accordingly with a central memory (CM) $\mathrm{T}$ cells phenotype representing mature long-lived lymphocytes with a high proliferative and migratory potential [3]. SS cells carry recurrent chromosomal alterations as loss of $17 \mathrm{p}, 10 \mathrm{q}, 19 \mathrm{p}$ and gains of $17 q, 8 / 8 q$ [4-6] and deep sequencing studies have identified mutations in genes involved in epigenetic, DNA repair, cell cycle, apoptotic and TCR-signaling mechanisms [7-12]. Despite these findings, no specific therapy is available yet to treat SS [13].

SS cells grow poorly in vitro also in presence of multiple cytokines, growth factors, macrophages, dendritic and mast cells indicating that nutrients and signals released by tumor microenvironment are essential to support their proliferation and survival [14-18]. We previously demonstrated that the PTEN, that antagonizes the PI3K/AKT signaling [19], is commonly downregulated in SS [20] and that AKT is 
A

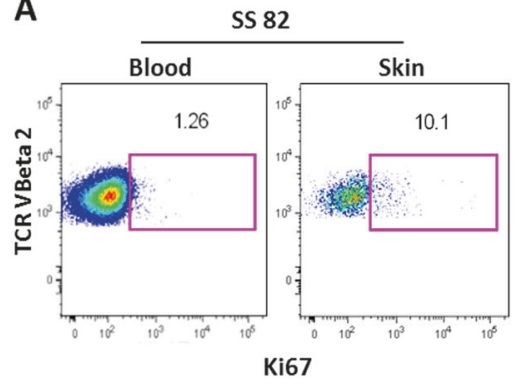

B

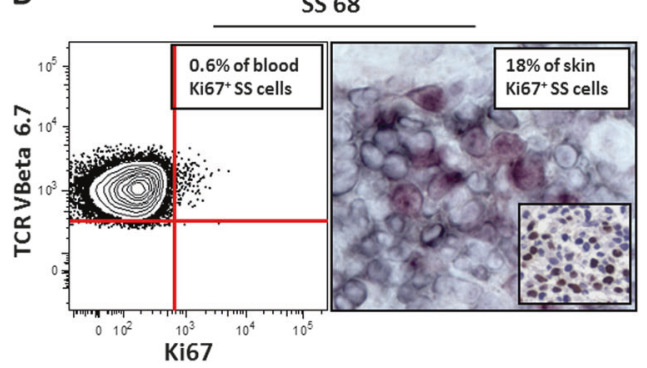

C

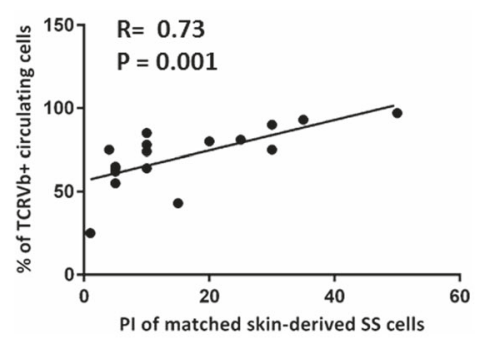

Fig. 1 Skin-derived SS cells show a higher proliferation-index (PI) compared to matched circulating SS cells, a data that correlates with tumor burden. a Fresh blood and skin-derived cells concurrently obtained from patient SS82 were analyzed by FACS and the percentage of Ki67+ SS cells (i.e., PI) was calculated within the neoplastic clone identified by CD3, CD4 and CCR7 positivity and co-expression of TCR-V $\beta 2$ chain rearrangement; $\mathbf{b}$ In SS68 patient, PI was measured by FACS within the TCR-V $\beta 6.7$ clone and in matched OCT skin biopsy by double IHC where KI67+ SS cells were recognized by a co-

mainly activated in skin tumor cells with respect to blood [20]. These data underline how different environments, as skin and blood, may affect SS cells in response to stimulatory or co-stimulatory signals [20].

Here, we compared skin to blood-derived SS cells concurrently obtained from SS patients to investigate the effect of the microenvironment on SS cells in vivo. This approach allowed us to identify the PI3K/AKT/mTORC1 activation in skin-resident SS cells, a pathway already found altered in CTCL by others $[21,22]$, that we also analyzed at the genomic and biochemical level in SS cell lines and primary tumor cells.

\section{Materials and methods}

\section{Patients and CTCL cell lines}

This study was conducted in accordance with the Declaration of Helsinki and approved by theEthical Committee of the Istituto Dermopatico dell'Immacolata (ID n. 4/CE/ 2015). Diagnosis of SS was based on described criteria [1]. Matched SS cell derived from blood and skin were concurrently obtained from SS patients and analyzed in parallel. SS cell isolation from blood was performed as previously described [5]. For samples with a TCR-V $\beta+$ clonality $\geq 90 \%$, CD4+ neoplastic cells were not purified, otherwise we selected them using the CD4+ untouched separation protocol (Miltenyi Biotech, Germany). In all experiments performed in this study, the primary tumor cells were indicated as SS cells. Isolation of SS cells from fresh skin punches of SS patients was performed by overnight incubation at $37^{\circ} \mathrm{C}$ in RPMI 1640 supplemented with $10 \%$ fetal bovine serum (FBS) (Sigma-Aldrich St. Louis, MO, USA) and $1 \mathrm{mg} / \mathrm{ml}$ Collagenase type IV (Worthington, staining with specific anti-TCR-V $\beta 6.7$ (black) and anti- Ki67 (purple) antibodies; in the insert, IHC for Ki67 performed on matched paraffinskin biopsy in which neoplastic cells were recognized for morphologic features by hematoxylin counter-staining. In IHC experiments, Ki67+ SS cells were calculated by a pathologist, counting at least 400 tumor cells in high-power fields with a 40x object lens; c A positive correlation between matched skin-PI values and tumor burden expressed as expansion of circulating clonal TCR-V $\beta+$ cells was also observed ( $n=17, R=0.73, P=0.001$ for Spearman test)

Lakewood, NJ). Skin-resident SS cells were isolated from fresh-frozen OCT-embedded skin biopsies using a laser micro-dissector (PALM Microlaser System, Bernried, Germany). All biopsies were selected from the files of IDI Pathology and specimens were classified according to the EORTC classification [1].

Clinical characteristics of SS patients used in matched analyses, in vitro signaling, cell proliferation assay and chemotaxis are shown in Supplementary Table S1 and S2.

Hut78 (TIB161), H9 (HTB 176) and HH (CRL2105) cell lines established from peripheral blood of CTCL patients were obtained from American Type Culture Collection (ATCC).

\section{Immunohistochemistry (IHC)}

IHC analyses for CD4 (1:20; Monosan,Uden, The Netherlands) and Ki67 (1:100, Dakocytomation, Glostrup, Denmark), were performed as described; [23] detection of phosphorylated (p) P70S6K(Thr389)(1:20.000, Abcam, Cambridge, UK) was done using Immpress HRP-Polymer detection kit (Vector Laboratories, Burlingame, CA) on cytospins of primary SS and $\mathrm{H} 9$ cells suspension fixed with $4 \%$ of Paraformaldehyde (Sigma-Aldrich) and paired paraffin- skin-biopsies. Double staining was performed as described in Supplementary Information

\section{Results}

\section{Skin-derived SS cells show a higher proliferation- index than matched circulating SS cells}

We analyzed by IHC the expression of the proliferation marker Ki67 on 17 SS skin biopsies. The percentage of 
A
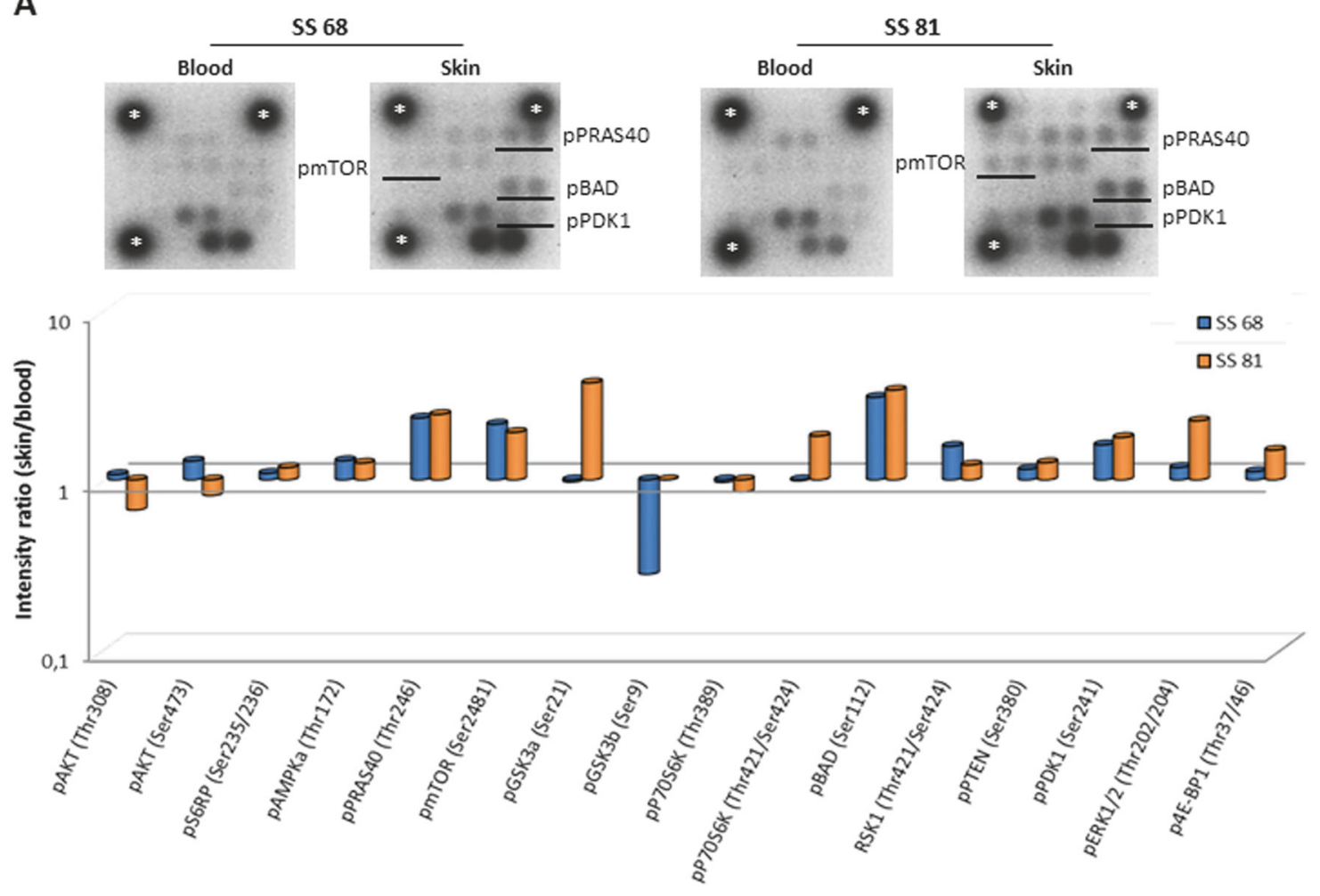

B
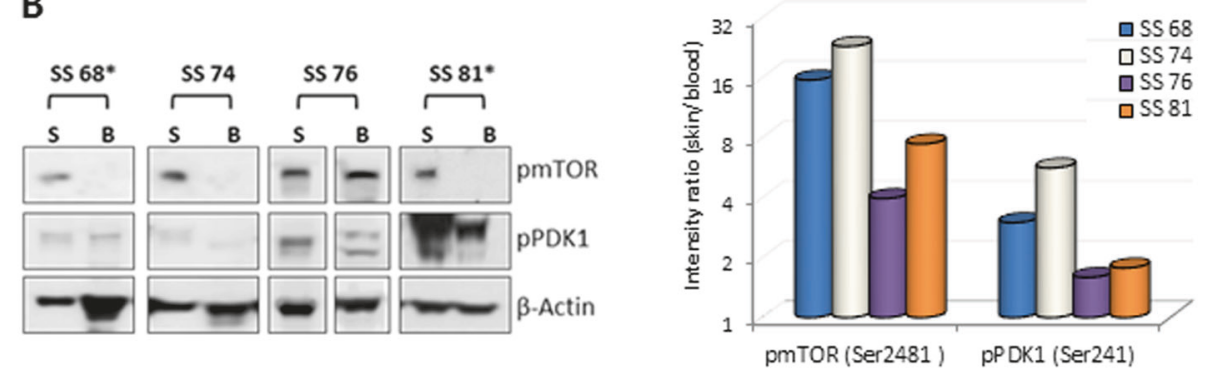

C

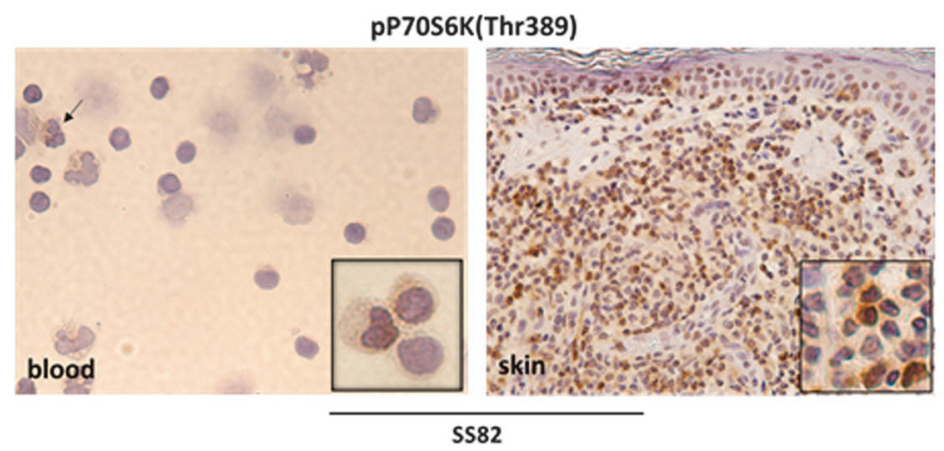

Ki67+ neoplastic cells (the Proliferation Index, PI) varied from 5 to $50 \%$ (mean $16.23 \pm 13.38$ ). We also measured the PI by FACS on 11 blood-derived SS samples and it ranged from 0.64 to $5 \%$ (mean $1.63 \% \pm 1.29$ ). (Table S1). These results indicated that the PI values were clearly different between skin and blood $(P<0.001)$. However, since this counting was evaluated on SS cells deriving from two different compartments by two different techniques, we compared the PI of matched skin and blood samples concurrently obtained from eight SS patients. In these cases, the percentage of Ki67 + SS cells was calculated, using a gating strategy, within the neoplastic clone recognized by the co-expression of CD3, CD4, CCR7 and the specific rearrangement of TCR-V $\beta$ chain by FACS (three samples) as 
Fig. 2 Comparison of phosphorylation levels of members of PI3K/ AKT pathway between matched circulating and skin-resident SS cells. a upper panel, a phospho-proteins kinase array was probed with protein lysates of blood and skin-derived SS cells concurrently obtained from 2 SS patients. The dots corresponding to p-mTOR, p-PRAS40, pBAD and p-PDK1 were indicated with black lines. Housekeeping protein is represented by *. a lower panel, graph represents the densitometric values of dots corresponding to each protein normalized to housekeeping and expressed as fold change (FC) with respect to matched blood SS cells. b left panel, WB validation for indicated proteins was accomplished in matched skin $(\mathbf{S})$ and blood (B) SS cells of four SS patients. Because of the timing of patient recruitment, the gels were run at separate times and the lanes were composed for the figure. b right panel, graph represents the densitometric values of normalized phosphorylated proteins expressed as FC with respect to matched blood SS cells. c IHC for pP70S6K shows a weak positivity in $4 \%$ of circulating SS cells and an intense positivity in about $70 \%$ of skin-resident SS cells concurrently obtained from patient SS 82. Inserts show SS cells at higher magnification. A weak positivity is also observed in neutrophil cells (arrow)

showed in Figure S1 and by double IHC (five samples) (two representative cases are shown in Fig. 1a, b). In these matched cases we confirmed that skin-derived SS cells exhibited a higher PI respect to blood-derived SS cells $(n=8,11 \pm 15 \%$ versus $1.9 \pm 1.4 \%$; fold change $(\mathrm{FC})=$ $5.8 ; P=0.01)$. To note that PI values obtained by IHC for Ki67 were comparable with those obtained by dual IHC (see 8th and 9th columns of the Table S1). We then correlated the PI values of the $17 \mathrm{SS}$ paraffin-skin biopsies with matched clinical data available as CD4/CD8 ratio, eosinophil count, percentage of circulating clonal TCR-V $\beta+$ cells and survival. Results obtained revealed a significant direct relationship between PI of skin-derived SS cells and the tumor burden expressed as percentage of circulating clonal $\mathrm{V} \beta+$ cells concurrently measured in these individuals $(n=$ $17, R=0.73, P=0.001$ ) (Fig. 1c and Table S1).

\section{Skin-derived SS cells show a higher level of mTOR activation than matched circulating SS cells}

Next, we analyzed in detail the pathway of PI3K/AKT/ mTOR that regulates proliferation and survival in matched skin and blood SS cells. For this purpose, the protein of blood and skin purified SS cells of SS68 and SS81 individuals were used in a pairwise-comparison of phospho levels of 16 members belonging to $\mathrm{PI} 3 \mathrm{~K} / \mathrm{AKT} / \mathrm{mTOR}$ pathway [24] using a kinase array (Fig. 2a). The results, expressed as FC values calculated using the matched circulating SS cells as reference, indicated an enhanced activation of many components of this cascade in skin-derived cells. Higher skin FC values (from 1.61 to 3.38) were observed in both patients for PRAS40(Thr246), an inhibitory subunit of mTORC1, mTOR(Ser2481), that phosphorylated in this position may represent both mTORC1/2 complexes [25, 26] $\mathrm{BAD}($ Ser112) that, in this status, abrogates its pro-apoptotic activity and PDK1(Ser241) which is a 3-phosphoinositide dependent kinase traditionally linked to AKT activation [24] (Fig. 2a).

We found, only in patient SS81, a hyper-phosphorylation of the multifunctional kinase GSK3A(Ser21) $(\mathrm{FC}=3.73)$, of p70S6K(Thr421/Ser424) which is a direct downstream member of mTORC1 $(\mathrm{FC}=1.81)$ and of ERK1/2, a central component of RAS/MAP kinase signaling involved in motility and proliferation $(\mathrm{FC}=2.23)$. With the exceptions of GSK3B(Ser9) showing higher activation in circulating cells with a FC of 0.28 in SS68, all other members of the cascade displayed comparable phosphorylation levels between blood and skin-derived SS cells (Fig. 2a).

Among the more skin-activated members, we validated mTOR and PDK1 on four patients (Table S1). Results obtained confirmed a higher phospho levels in skin of mTOR(Ser2481), with FC values ranging from 3.9 to 22.9, and PDK1(Ser241) with FC ranging from 1.6 to 5.6 in all samples (Fig. 2b left and right panel). Validation of pERK confirmed its skin hyper activation in all three patients analyzed with FC values ranging from 1.2 to 12.8 (Fig. S3). Additionally, we evaluated the activation of mTORC1 signaling by IHC detection of its downstream member, pP70S6K(Thr389), on additional three paired skin-blood samples (Table S1) and H9 cells used as positive control (Fig. S4). Compared to above kinase data, pP70S6K (Thr 389) appeared more expressed in skin respect to matched blood SS cells in all three cases studied possibly reflecting a clinical heterogeneity and/or different therapeutic treatments among patients analyzed and/or the different techniques used to perform these experiments. One out of three cases analyzed is showed in Fig. 2c.

\section{SDF-1 and CCL21 chemokines activate mTORC1 pathway, promote tumor proliferation and up- regulate the Ki67 expression in $\mathrm{H} 9$ cell line and primary SS cells}

mTOR is a central environmental sensor that integrates survival/proliferation and metabolism signals. It represents the catalytic subunit of TORC1 and TORC2, two distinct complexes linked by a negative feedback loop, able to regulate different functions and downstream targets [27]. The above described results indicated that both complexes are activated in skin-derived SS cells; however, the finding that TORC1 pathway is triggered in cancer cells by SDF-1 and CCL21 [28-30], two chemokines highly expressed in SS tissues and able to chemoactract SS cells in vitro [23, 37] prompted us to investigate in detail this mechanism. To mimic skin conditions, we stimulated the $\mathrm{H} 9$ cells and primary SS cells with SDF-1 and CCL21 to analyze the activation level of mTORC1 downstream members. A significant increase of the level of phosphorylation of P70S6K 


\section{H9 cell line}
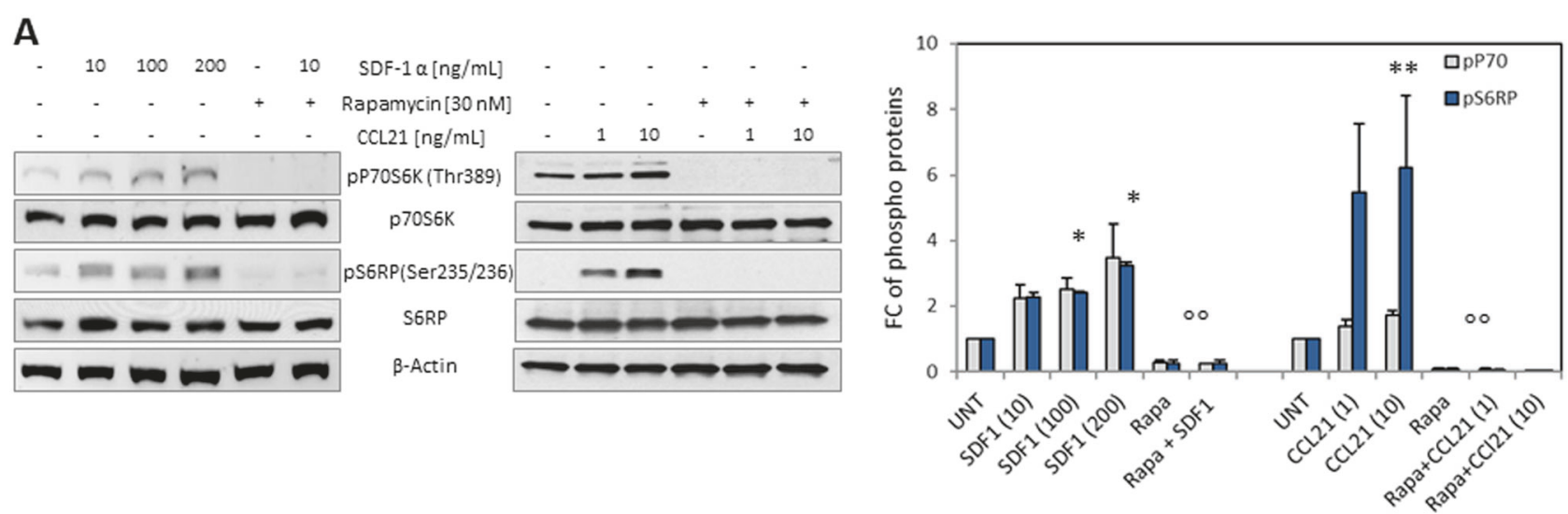

SS patients
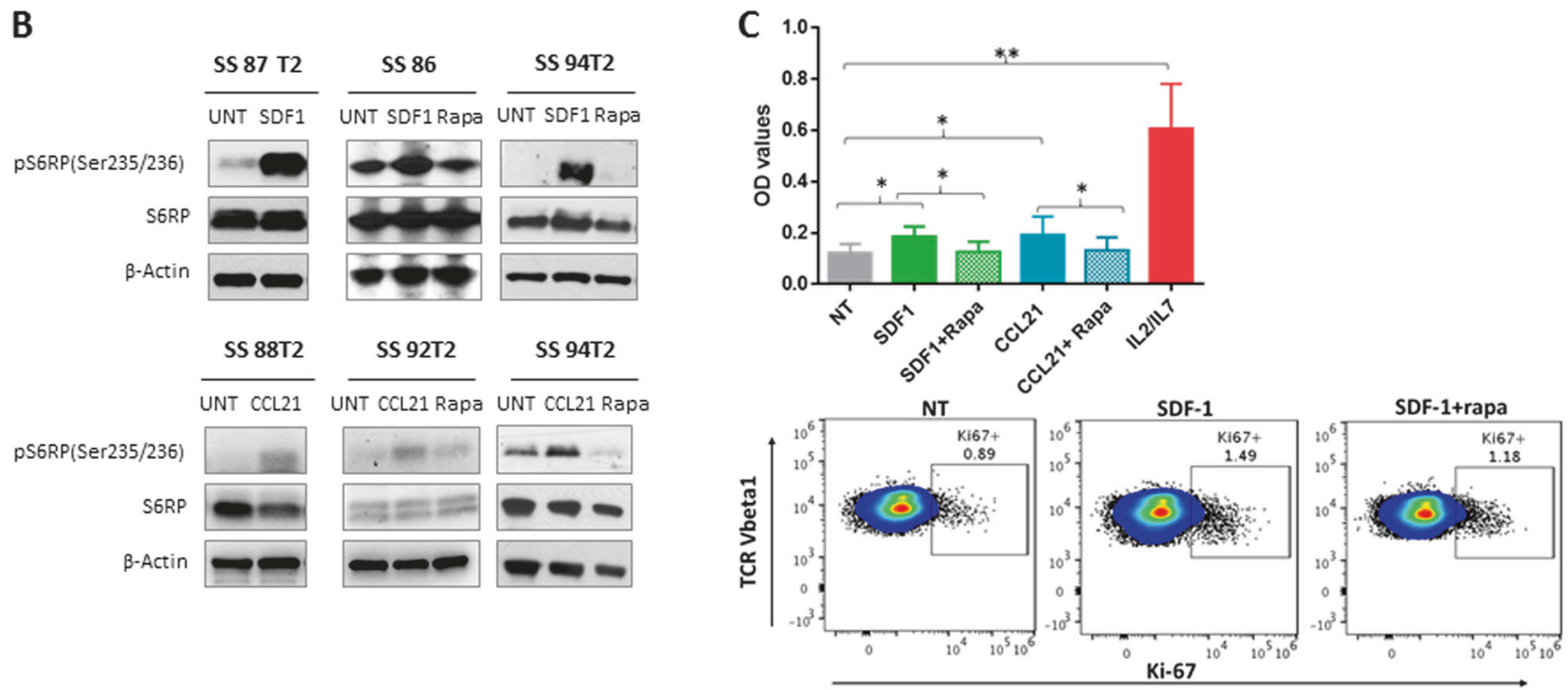

Fig. 3 SDF-1 and CCL21 chemokines activate mTORC1 pathway, promote tumor proliferation and up-regulate the Ki67 expression in $\mathrm{H} 9$ cell line and primary SS cells. a left panel, serum-starved H9 cells were left untreated (UNT) or pre-incubated with rapamycin for $2 \mathrm{~h}$ and then stimulated or not with SDF-1 or CCL21 for $30 \mathrm{~min}$ at indicated concentrations. WB was performed for the specified proteins. a Right panel, densitometric data normalized to $\beta$-actin were expressed as mean \pm SEM of three independent experiments. Graph shows phospho protein levels expressed as FC respect to UNT samples $* \mathrm{P} \leq$ $0.02, * * P=0.05 ;{ }^{\circ} P \leq 0.0001 ; \mathbf{b}$ upper panel, SS cells from patients cultured in complete medium at high density, left UNT or preincubated with $30 \mathrm{nM}$ of rapamycin for $2 \mathrm{~h}$ and then stimulated or not for $30 \mathrm{~min}$ with $100 \mathrm{ng} / \mathrm{ml}$ of SDF-1 or $\mathbf{b}$ lower panel,with $10 \mathrm{ng} / \mathrm{ml}$ of

(pP70S6K) and S6RP (pS6RP) was observed after $30 \mathrm{~min}$ of H9 stimulation with both chemokines compared to untreated cells. Both phosphorylations were significantly inhibited by a $2 \mathrm{~h}$ pretreatments with rapamycin, the specific inhibitor of mTORC1 [31] (Fig. 3a). As P70S6K can directly phosphorylate PDCD4 promoting its degradation
CCL21. WB was performed for the specified proteins. Because of the timing of patient recruitment, the gels were run at separate times and the lanes were composed for the figure. $\mathbf{c}$ upper panel, SS cells were cultured in vitro at high density for 5 days in complete medium used alone (NT) or supplemented with $300 \mathrm{ng} / \mathrm{ml}$ of SDF-1 or CCL21 in presence or absence of rapamycin used at $30 \mathrm{nM}$ or IL 2 at $30 \mathrm{U} / \mathrm{ml}$ plus IL7 at $10 \mathrm{ng} / \mathrm{ml}$. Cell proliferation was determined by MTT assay and data are expressed as means of OD values \pm SEM. Statistics were calculated as paired t-test. $* P=0.05 ; * * P=0.01$; $\mathbf{c}$ lower panel, cellactivation induced by $300 \mathrm{ng} / \mathrm{ml}$ of SDF-1 was evaluated in SS cells obtained from SS94 patient, by Ki67 detection using FACS within neoplastic clone recognized by CD3,CD4, CCR7 and TCR-V $\beta 1$ chain rearrangement

and releasing the inhibitory effect on the initial step of protein translation [32], we next evaluated the phosphorylated and non-phosphorylated form of this protein in $\mathrm{H} 9$ cells exposed to SDF-1 for different times. After 30 min we observed an increase of pPDCD4 level that was inhibited by 2 hours (h) of rapamycin pretreatment whereas an increase 
A

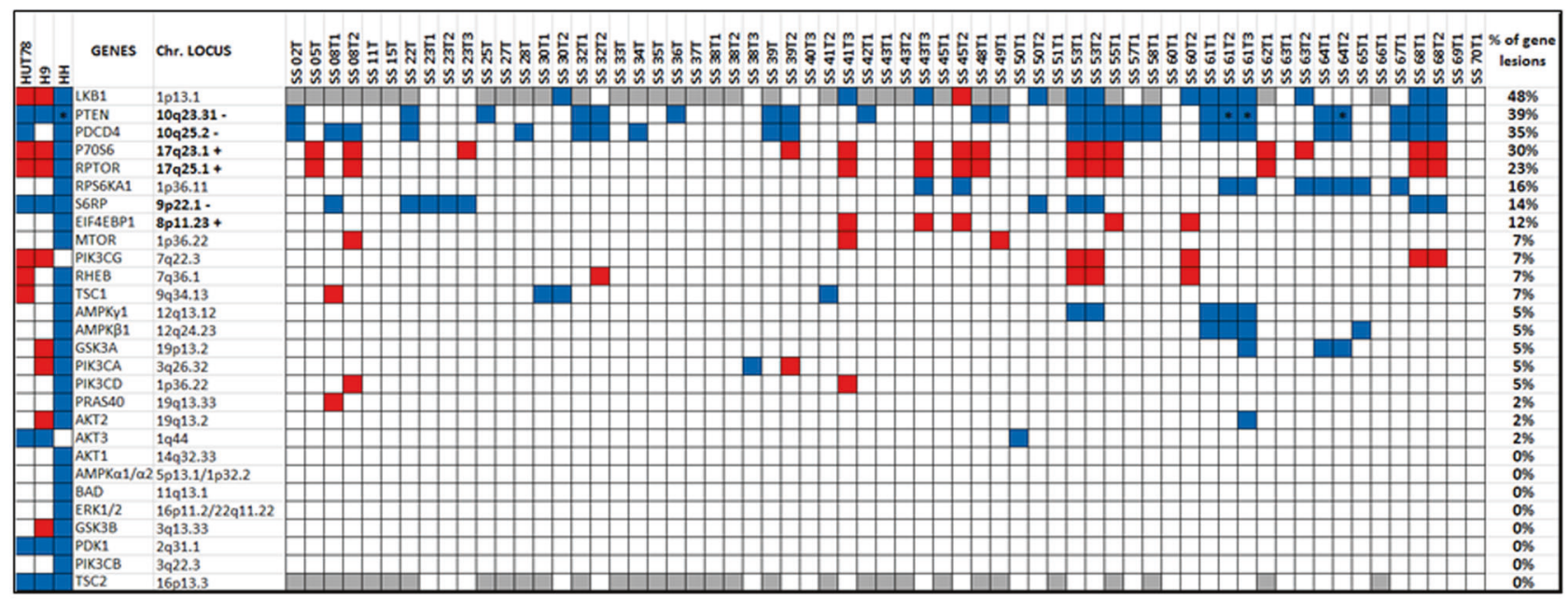

B

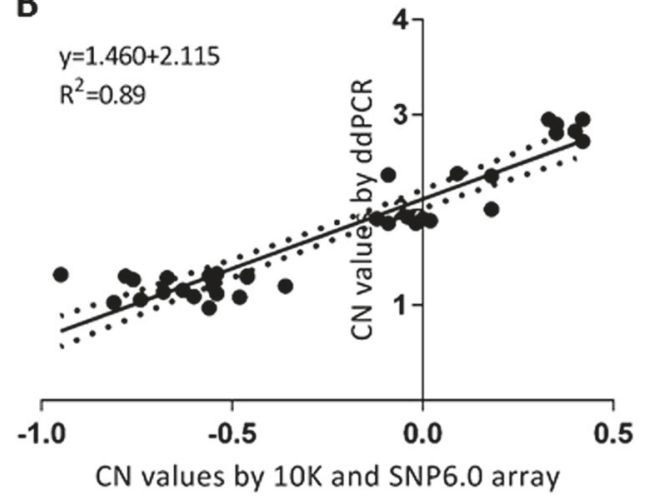

Fig. 4 Frequency of $\mathrm{CN}$ changes of members belonging to PI3K/AKT/ mTOR pathway observed in a cohort of 43 SS patients. a $\mathrm{CN}$ data were obtained using Affymetrix $10 \mathrm{~K}$ and SNP6.0 platforms. Monoallelelic gains and losses are represented in red and blue, respectively. Bi-allelic loss is indicated as*. Genes not covered by $10 \mathrm{~K}$ array are represented in gray. Percentages reflect the lesion frequency observed for each gene. b CN values for PDCD4, LKB1 and P70S6K genes obtained by ddPCR versus $10 \mathrm{~K} / \mathrm{SNP} 6.0$ arrays on a total of

of PDCD4 level, able to block protein synthesis [32], was observed after a longer rapamycin exposure peaking after $24 \mathrm{~h}$ (Fig. S5). Then, to verify that mTORC1 activation occurs also in primary malignant lymphocytes we analyzed freshly circulating SS cells from five patients (Table S2). Also in this system we observed an increase of pS6RP level in response of $100 \mathrm{ng} / \mathrm{ml}$ of SDF-1 and $10 \mathrm{ng} / \mathrm{ml}$ of CCL2 1 that was inhibited by rapamycin (Fig. 3b). Lastly, we wondered if these chemokines also promoted SS cells proliferation. Purified SS cells from 5 patients (Table S2), cultured at high density in complete medium with or without SDF-1 or CCL21, demonstrated that both chemokines significantly enhanced proliferation, although to lesser extent than T-cell growth factors like IL2/IL7; we assessed that rapamycin inhibited this chemokine-induced effect (upper panel, Fig. 3c). In two cases (Table S2), we also
30 samples plus diploid reference gDNA (Affymetrix) used as controls. Graph is based on a linear regression model. Solid line indicates the fitting curve. Dotted line represents 95\% confidence limits. $P=<$ 0.0001. c CN values for LKB1, PTEN, PDCD4 and P70S6K obtained by ddPCR on patients analyzed for kinase array validation $\left(^{\circ}\right)$ and mTORC1 in vitro signaling (*). Losses are represented in blue, gains in red

evaluated the cell-activation status induced by SDF-1 demonstrating that it up-regulated the Ki67 expression while rapamycin inhibited it (one representative case is shown in lower panel of Fig. 3c). Even if with less efficacy, CCL21 showed similar results (Fig. S6).

\section{SS patients show frequent genome copy number variations (CNVs) of members of the PI3K/AKT/ mTORC1 pathway}

Since we previously demonstrated that PTEN is deleted in $36 \%$ of SS individuals but no mutation was detected within its coding region [20], we wondered if and how often additional genetic mechanisms potentially leading to $\mathrm{PI} 3 \mathrm{~K} /$ AKT/mTOR pathway dysregulation occurred in SS. With this aim we investigated the $\mathrm{CN}$ status of the main members 
Fig. $5 \mathrm{CN}$ variations of PTEN, PDCD4 and P70S6K correlate with the outcome and define survival classes in SS. SS patients were identified by $\mathrm{CNV}$ of PTEN $(P=0.04)$, PDCD4 $(P=0.015)$ and P70S6K $(P=$ $0.0002)$ and analyzed by Kaplan Meier (KM) analysis. KM performed on four clusters of patients identified from the total number of lesions observed for these genes (from 0 to 3 ) showed a progressive shorter survival with increasing number of lesions $(P=0.002)$. Statistic was calculated by Log-rank test
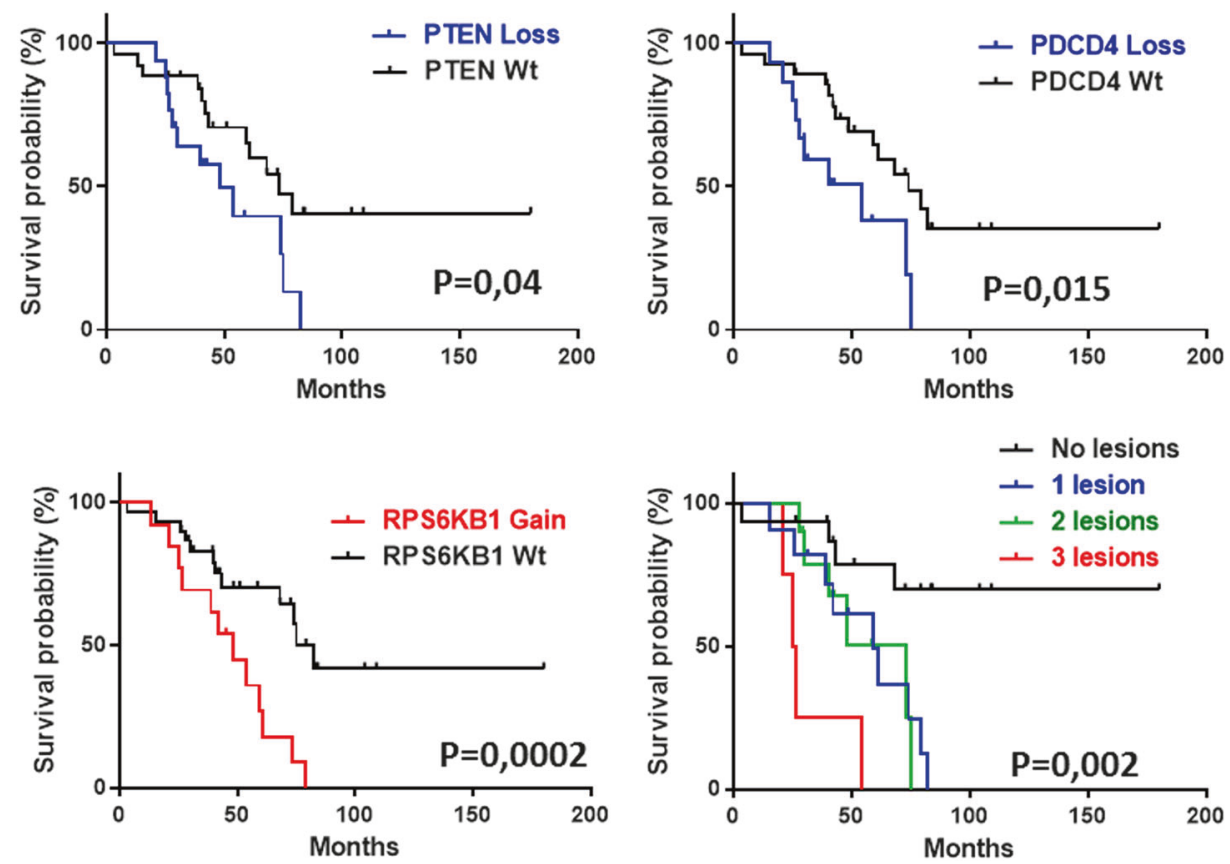

of this cascade using the Affymetrix arrays data of circulating tumor cells derived from 63 SS samples (43 patients plus 20 F-UP) and 3 CTCL cell lines [20]. We observed that many components of PI3K/AKT/mTOR pathway showed frequent deletions and amplifications that, with few exceptions observed for PTEN, appeared as monoallelic defects (Fig. 4a). We detected recurrent deletions involving TS genes representing upstream negative regulators of mTOR signaling: we found loss of LKB1 in 9 of 21 cases (48\%) as measured by the higher genome resolution SNP6.0 platform and we confirmed PTEN deletion in 17 of 43 cases (39\%) in agreement with our previous study [20]. Among the downstream members of mTORC1 pathway we found recurrent deletions of the TS PDCD4 in 15 of 43 cases (35\%), gains of the proto-oncogene P70S6K in 13 of 43 $(30 \%)$ and of RAPTOR in 10 of 43 cases $(23 \%)$ and deletions of P90S6K in 7 out 43 cases (16\%) (Fig. 4a).

Moreover, we found $\mathrm{CN}$ variations (CNV) of two other downstream effector members of mTORC1: loss of S6RP in 6 of $43(14 \%)$ and the gain of EIF4EBP1 (alias 4EBP1) in 5 of 43 cases (12\%). Other components of this pathway including mTOR, PIK3CG, RHEB, TSC1, AMPKG1, GSK3a, PI3KCA, PI3KCD, and PRAS40 showed a CNV at lower frequencies ranging from 2.3 to $7 \%$, whereas the remaining pathway components did not show any $\mathrm{CN}$ changes. $\mathrm{CN}$ abnormalities of multiple members of this signaling co-occurred also in $\mathrm{H} 9$, Hut78 and $\mathrm{HH}$ cell lines as shown in the left columns of Fig. 4a.

We validated $\mathrm{CN}$ values found for PDCD4, LKB1and P70S6K in 10 patientsby ddPCR. We obtained values ranging from 0.97 to 1.33 for $\mathrm{CN}$ loss (PDCD4 and LKB1), from 2.72 to 2.95 for $\mathrm{CN}$ gain (P70S6K) and from 1.85 to 2.38 for WT conditions (Table S3). Thus, ddPCR values were in agreement with those obtained with $10 \mathrm{~K}$ and SNP6.0 arrays as demonstrated by Pearson's correlation $(R=0.94, P<0.0001)$ and the linear regression $(P=$ 0.0001) (Fig. 4b).

Based on these results, we demonstrated by ddPCR that CN changes of PTEN, PDCD4, LKB1 and P70S6K occur also in SS patients used for phospho-array validation (Fig. 2c) and TORC1 activation signaling in vitro (Fig. 3b) as showed in Fig. 4c. Moreover, we confirmed CN changes of LKB1, PDCD4 and P70S6K by ddPCR also in the skinresident $\mathrm{SS}$ cells of three cases for whom we had genomic DNA: SS30T2, SS60T1 and SS81T1. The same CN status of these genes detected in circulating and skin-derived SS cells of these patients (Table S3) indicated that these two cellular subsets show a homogeneous genomic phenotype.

\section{Multiple CNV of members of the PI3K/AKT/mTOR pathway define survival classes in SS}

Patients with CN loss of PTEN ( $n=17)$, PDCD4 $(n=15)$ and $\mathrm{CN}$ gain of P70S6K $(n=13)$ revealed an unfavorable outcome compared to individuals with the corresponding WT status of these loci showing a median of overall survival (OS) of 48.4 months vs 73.1 months. $(P=0.04), 54$ vs 74 months $(P=0.015)$ and 48.4 vs 82 months $(P=0.002)$, respectively (Fig. 5). No significant difference in survival was seen for LKB1 deletions (data not shown) probably because of the smaller sample size analyzed by SNP6 array $(n=23)$. Kaplan Maier (KM) analysis revealed also a significant 


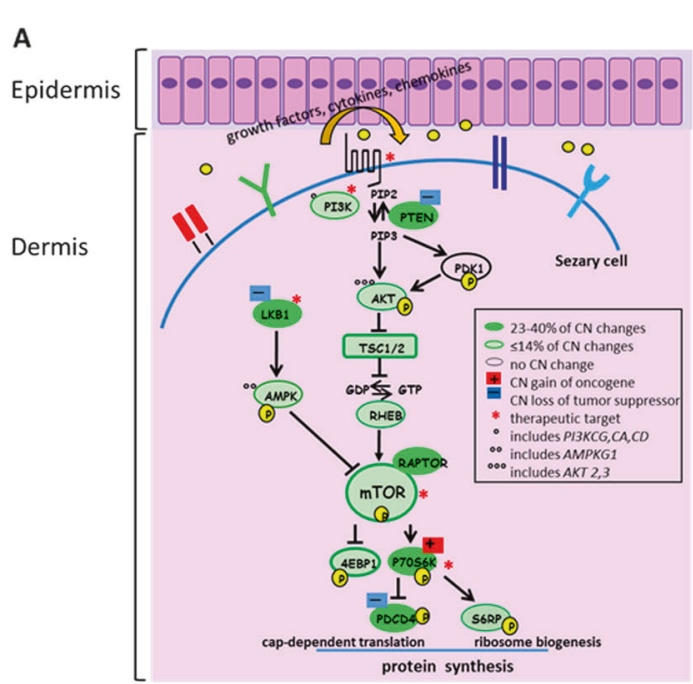

Fig. 6 Diagram of skin interaction with Sezary cells and effects of metformin in $\mathrm{H} 9$ cell line and primary SS cells. a Map of PI3K/AKT/ mTORC1 pathway including members $\mathrm{CN}$ changes found in $43 \mathrm{SS}$ individuals. Asterisks indicate therapeutic targets; b left panel, H9 cells untreated (UNT) or pre-treated for $2 \mathrm{~h}$ with metformin at $10 \mathrm{mM}$ and then stimulated or not for $30 \mathrm{~min}$ with SDF-1 at 10 and $100 \mathrm{ng} / \mathrm{ml}$ were analyzed by WB for indicated proteins as showed by one representative experiment. b right panel, densitometric data normalized to $\beta$-actin were expressed as mean \pm SEM of 3 independent experiments. Graph shows phospho protein levels expressed as FC respect to UNT samples $* P=\leq$ 0.05 . $\mathrm{c}$ H9 cells UNT or pre-treated for $2 \mathrm{~h}$ with metformin at $10 \mathrm{mM}$ or

difference in survival when patients were clustered in four distinct groups associated to: (a) no lesions found for PTEN, PDCD4 and P70S6K $(n=16)$; (b) a lesion affecting one gene of three $(n=13)$; (c) lesions involving two genes of three $(n=10)$; (d) lesions including all three genes $(n=4)$.

The resulting KM analyses demonstrated that SS patients without lesions in three genes were long survivors, those displaying one or two lesions showed a progressive shorter outcome with a median OS of 73 and 59 months, respectively, whereas patients with three lesions were associated with the worst clinical outcome with a median OS of 25.7 months $(P=0.002)$ (Fig. 5).

\section{Metformin inhibits mTORC1 signaling and migration of SS cells induced by SDF-1}

Genome alterations found here suggest that the losses of TSs as PTEN, LKB1 and PDCD4 as well as the gain of the oncogene P70S6K might converge toward an increased oncogenic activity of PI3K/AKT/mTORC1 signaling and that many members might represent novel therapeutic targets to treat SS (Fig. 6a) [33]. Among these, we focused on TS LKB1, that represents the most altered gene with a loss in $48 \%$ of cases studied. LKB1 is a kinase that activates AMPK that, in turn, inhibits the mTOR signaling [34].
H9 Cell Line

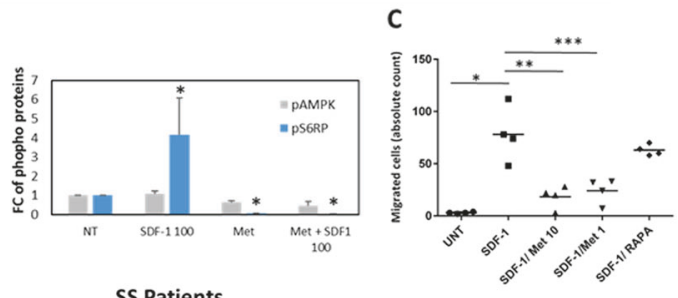

SS Patients

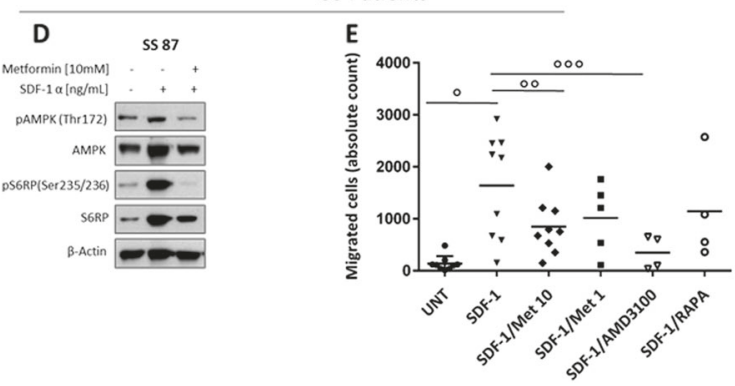

$1 \mathrm{mM}$ or rapamycin at $30 \mathrm{nM}$ were allowed to migrate in response of SDF-1 used at $300 \mathrm{ng} / \mathrm{ml}$. d SS cells left UNT or $2 \mathrm{~h}$-pretreated with metformin and then stimulated with SDF-1 at $100 \mathrm{ng} / \mathrm{ml}$ were analyzed by WB as above described as showed by one representative experiments; e SS UNT or pre-treated for $2 \mathrm{~h}$ with $10 \mathrm{mM}$ or $1 \mathrm{mM}$ of metformin or AMD3100 at $15 \mu \mathrm{M}$ or rapamycin at $30 \mathrm{nM}$ were allowed to migrate in response to SDF-1 at $300 \mathrm{ng} / \mathrm{ml}$. In both systems, migration results are shown as an absolute number of $\mathrm{CD}^{+}$migrated cells measured by flow cytometry. Each dot represents a sample; bars represent the mean of migration counts. ${ }^{*} P=0.01,{ }^{\circ} P=0.0014$; $* *$ and ${ }^{\circ \circ}$ and $* * * ;{ }^{\circ}{ }^{\circ} P \leq$ 0.05 were calculated by paired $t$-test

Drugs able to activate AMPK are therefore useful to fight the hyperactive mTORC1 signaling and one of the most commonly used is metformin, a repurposing antidiabetic drug with direct antitumor properties [35]. Beyond glycemic control, metformin inhibits mTORC1 signaling by AMPK activation via LKB1 or by an AMPK-independent mechanism, for example in a ragGTPase-dependent manner $[35,36]$. As the recurrent $\mathrm{CN}$ loss of LKB1 here described might prejudice the LKB1/AMPK axis function in SS, we wondered if metformin could have an effect on mTORC1 signaling in this neoplasia. With this purpose, we analyzed metformin pretreated $\mathrm{H} 9$ cells $(n=3)$ and primary SS cells $(n=2)$ stimulated or not by SDF-1 that we found more abundant in SS skin than CCL21, which is mainly expressed in endothelial cells [37]. In both systems, $2 \mathrm{~h}$ exposure of metformin prevents mTORC1 activation as demonstrated by the inhibition of S6RP phosphorylation by a mechanism that appears to be AMPK-independent (Figs. 6b, d and Fig. S7).

Metformin also inhibits chemotaxis of cancer cells through mechanisms still not well understood [38]. As SS cells express several chemokine receptors including CXCR4 and CCR7 $[23,39]$ and they migrate in vitro in response to SDF-1 and CCL21 [23, 37], we investigated the effect of metformin on SS cells chemotaxis. Using a 
transwell assay we observed that metformin at $10 \mathrm{mM}$ and $1 \mathrm{mM}$, significantly inhibited $\mathrm{H} 9$ cell migration towards SDF-1 whereas a minor effect was observed with $30 \mathrm{nM}$ rapamycin pretreatment (Fig. 6c). Similarly, SS cells obtained from patients (Table S2) were significantly inhibited with pretreatments of metformin used at $10 \mathrm{mM}$ $(n=9)$ or $1 \mathrm{mM}(n=5)$ (Fig. 6e). A significant inhibition was also observed with $15 \mu \mathrm{M}$ of AMD3100, an antagonist of CXCR4 that we used to verify the specificity of CXCR4$\operatorname{SDF}-1 \operatorname{binding}(n=4)$ whereas rapamycin at $30 \mathrm{nM}$ interfered less also with chemotaxis of SS cells $(n=4)$ (Fig. 6e). This lower effect suggests that rapamycin, beyond mTOR pathway $[30,40]$, interferes less with other signaling(s) involved in locomotion respect to metformin. We also proved that metformin inhibits chemotaxis toward CCL21 (Fig. S8).

Lastly, in agreement with the cytostatic effect of metformin, we observed a significant reduction of cell viability in CTCL cell lines but not in low proliferating primary circulating SS cells after metformin treatment, as demonstrated by MTT and FACS analysis (Fig. S9).

\section{Discussion}

Previous studies have described SS cells as quiescent and apoptotic-resistant malignant lymphocytes classifying SS principally as an accumulative disorder [15, 41]. Although earlier studies using tritiated thymidine labeling in vivo generically indicated a higher SS cells proliferation in skin and lymph nodes [42] here we demonstrated, with more accuracy, to what extent the skin-resident SS cells proliferate more respect to those of blood using the Ki67 analysis, a widely recognized marker of cell activation/ proliferation in daily pathologic practice [43]. We also observed that skin PI increases with the expansion of tumor burden measured as blood TCR-V $\beta$ clonality indicating that skin and blood compartments are interconnected, thus supporting the concept that activation/proliferation plus apoptosis resistance could determine the SS clinical outcome.

Another key purpose of this study was to identify which members of the PI3K/AKT/mTOR signaling are engaged in vivo in SS. Using a skin-blood comparison approach, we found that skin-derived SS cells mainly show a higher level of mTORC1/mTORC 2 activation than corresponding circulating SS cells. In CTCL, the involvement of TORC1 is already demonstrated by studies conducted on rapamycin, a compound that mainly inhibits this complex [31], able to reduce proliferation of CTCL cell lines, primary tumor cells [21] and tumor size in xenograft mice [22]. Recent investigations demonstrated that SDF-1 and CCL21 chemokines through their cognate receptors CXCR4 and CCR7, signals to mTOR pathway in other cancers [28-30]. As SS cells express several chemokine receptors [23, 37, 39] including CXCR4 which is involved in metastatic processes and CCR7 that is responsible for lymph-node homing [44], we demonstrated that both SDF-1 and CCL21 activate mTORC1 also in this malignancy. The importance of this finding is supported by the ability of SS cells to migrate in response to SDF-1 and CCL21/19 which are overexpressed (SDF-1 over CCL21) in SS skin [37]. Since SS cells do not express SDF-1 mRNA, but rather they seem to uptake the SDF-1 released from epithelial, dendritic and endothelial cells of the skin [23], we can speculate that SS cells move toward skin through a chemotactic gradient [23]. This hypothesis is further reinforced by the lack from SS cell surface of CD26 peptidase able to cleave and inactivate SDF-1 [23], by the versican overexpression, a proteoglycan that enhances the SS locomotion toward SDF-1 [45] and by the comparable levels of plasmatic SDF-1 found between HDs and SS individuals (data not shown).

These results underline that, beyond migration, these chemokines activate the TORC1signaling, pointing toward processes as protein translation and cellular energy [46]. Moreover, similarly to what demonstrated on healthy CD4+ lymphocytes [47, 48] SDF-1 and CCL21 promote proliferation and up-regulate Ki67 expression in SS cells underlying the more activated phenotype of skin resident respect to blood SS cells recently observed by Roelens et al. [49]. Rapamycin inhibited both processes indicating that both SDF-1 and CCL21 induce activation/proliferation by a mTORC1-dependent mechanism(s) that have yet to be clarified

Using SNP technology we also explore the PI3K/AKT/ mTOR pathway at the genomic level. We found multiple $\mathrm{CNV}$ of members belonging to this cascade that map within large genomic regions described as recurrently unbalanced in SS as 10q and 17q chromosome (chr) [4-6]. Accordingly with these findings, we observed concurrent $\mathrm{CN}$ losses of PTEN and PDCD4, both localized at chr 10q23-25, in 30\% of the cases as well as concomitant $\mathrm{CN}$ gains of P70S6K and RAPTOR, both mapping at chr 17q23-25 in $23 \%$ of the samples analyzed. In addition, it is interestingly to note that CNV of the pathway downstream members represented by RPS6 and 4EBP1 genes, respectively involved in capdependent translation and ribosome biogenesis [32, 46], occurred in mutually exclusive manner; thus suggesting that SS patients may cluster respect to these gene alterations leading toward different routes of protein synthesis. CNVs assume a very important role in SS since they appear more common than TS/oncogene mutations with respect to other cancers [50]. Accordingly with this feature, the SNPs [20] and the latest NGS analyses $[9,11]$ revealed no or very few mutations within PTEN coding region of SS individuals while the $\mathrm{CN}$ loss of this gene, either in mono or biallelic 
defect, is a frequent event ranging from 20 to $36 \%$ of cases $[10,12,20]$. Absence or very low frequency mutations detected by NGS in LKB1, P70S6K and PDCD4 genes in CTCL/SS lymphomas [10, 12] furthermore support this hypothesis. The importance of $\mathrm{CNV}$ in $\mathrm{SS}$ is also reinforced by the significant correlation between $\mathrm{CN}$ changes and overall survival here demonstrated, indicating these alterations as novel prognostic markers that potentially reflect the alterations of the $10 q 23$ and $17 q 23$ loci on which they map.

mTORC1 regulates protein synthesis and metabolism, two interconnected routes which appear strongly compromised in SS. In fact, in this study we found CNV of both P70S6K and PDCD4 that might reflect a dysfunction of mTORC1-dependent protein synthesis leading to an increased cell size that might explain the larger SS cell dimensions often observed [1, 51]. Moreover, we detected recurrent loss of PTEN that under normal conditions attenuates the upstream activation of mTORC1 through PIP3 dephosphorylation [52] and loss of LKB1, that normally is able to activate AMPK, a kinase that inhibits mTORC1 in low energy conditions [34, 53]. These genomic defects might result in stoichiometric unbalance ultimate leading to a constitutive TORC1 activation promoting a metabolic shift: from oxidative phosphorylation, mainly observed in quiescent/memory lymphocytes toward aerobic glycolysis that increase the glucose demand (Warburg effect) typically observed in activated lymphocytes [53]. Accordingly, rapamycin inhibits tumor growth decreasing aerobic glycolysis in a mouse model of CTCL [54]. Considering the trafficking ability of SS cells [23, 37, 39] these genomic dysfunctions promoting aerobic glycolysis and protein translation might be functionally useful, in term of energy, during the SS cells recruitment to skin and/or lymph node by SDF-1 and CCL21, both able in turn, to promote mTORC1 activation signaling and proliferation of these cells. In summary, these results indicate that the genomic changes here identified might be insufficient to induce SS cell proliferation and emphasize the role of factors present within the skin like cytokines [55], antigens able to engage T-Cell Receptor [56] and the SDF-1 and CCL21 chemokines here studied.

Members of this signaling with $\mathrm{CN}$ changes represent, for SS, both novel (as LKB1, P70S6K) and already known (as PI3K, mTOR) therapeutic targets [33]. Actually, the efficacy of rapalogs and dual PI3K/mTOR inhibitors have been largely proven in vitro in T-cell lymphoma $[57,58]$ but, despite these results, few clinical trials in CTCLs are ongoing (http://www.tcllfoundation.org/current-clinical-trials. Detection of several genomic alterations in PI3K/AKT/mTORC1 pathway indicates that other specific compounds can be tested as the metformin that we demonstrated to inhibit in vitro mTORC1 activation and chemotactic ability of SS cells. Recognition of these lesions might, moreover, improve patient stratification for clinical trials enrollment of SS patients.

Acknowledgements This study was supported by the Associazione Italiana per la Ricerca sul Cancro (M.G.N. and G.R.), Ministero della Salute and Associazione Volontari per il Policlinico Tor Vergata, ONLUS. The authors thank Gabriele Alvetreti and Emiliano Ferranti for nursing assistance, Dr. Laura Todi for experimental support, Domenico Rosi and Barbara Iacomino for immunohistochemistry analyses and Prof. Massimo Fiorilli and Prof. Enzo Bonmassar for continuous scientific support.

Author contributions CC, AB, MP, MCP, FM, MHC, EC, and MGN performed experiments and analyzed data; $\mathrm{AM}, \mathrm{MC}$, and $\mathrm{RB}$ recruited eligible patients and collected clinical information; FP evaluatedpathologic specimens; MGN, CC, and AB analyzed data; MGN, $\mathrm{SD}, \mathrm{EC}$, and GR wrote and/or revised the manuscript.

\section{Compliance with ethical standards}

Conflict of interest The authors declare that they have no conflict of interest.

Open Access This article is licensed under a Creative Commons Attribution 4.0 International License, which permits use, sharing, adaptation, distribution and reproduction in any medium or format, as long as you give appropriate credit to the original author(s) and the source, provide a link to the Creative Commons license, and indicate if changes were made. The images or other third party material in this article are included in the article's Creative Commons license, unless indicated otherwise in a credit line to the material. If material is not included in the article's Creative Commons license and your intended use is not permitted by statutory regulation or exceeds the permitted use, you will need to obtain permission directly from the copyright holder. To view a copy of this license, visit http://creativecommons. org/licenses/by/4.0/.

\section{References}

1. Olsen EA, Whittaker S, Kim YH, Duvic M, Prince HM, Lessin $\mathrm{SR}$, et al. Clinical end points and response criteria in mycosis fungoides and Sézary syndrome: a consensus statement of the International Society for Cutaneous Lymphomas, the United States Cutaneous Lymphoma Consortium, and the Cutaneous Lymphoma Task Force of the European Organisation for Research and Treatment of Cancer. J Clin Oncol. 2011;29:2598-607.

2. Scarisbrick JJ, Prince HM, Vermeer MH, Quaglino P, Horwitz S, Porcu P, et al. Cutaneous Lymphoma International Consortium Study of Outcome in Advanced Stages of Mycosis Fungoides and Sézary Syndrome: Effect of Specific Prognostic Markers on Survival and Development of a Prognostic Model. J Clin Oncol. 2015;33:3766-73.

3. Campbell JJ, Clark RA, Watanabe R, Kupper TS. Sezary syndrome and mycosis fungoides arise from distinct T-cell subsets: a biologic rationale for their distinct clinical behaviors. Blood. 2010;116:767-71.

4. Mao X, Lillington DM, Czepulkowski B, Russell-Jones R, Young BD, Whittaker S. Molecular cytogenetic characterization of Sézary syndrome. Genes, Chromosom Cancer. 2003;36:250-60.

5. Caprini E, Cristofoletti C, Arcelli D, Fadda P, Citterich MH, Sampogna $\mathrm{F}$, et al. Identification of key regions and genes important in 
the pathogenesis of sezary syndrome by combining genomic and expression microarrays. Cancer Res. 2009;69:8438-46.

6. Vermeer MH, van Doorn R, Dijkman R, Mao X, Whittaker S, van Voorst Vader PC, et al. Novel and highly recurrent chromosomal alterations in Sézary syndrome. Cancer Res. 2008;68:2689-98.

7. Choi J, Goh G, Walradt T, Hong BS, Bunick CG, Chen K, et al. Genomic landscape of cutaneous $\mathrm{T}$ cell lymphoma. Nat Genet. 2015;47:1011-9.

8. Ungewickell A, Bhaduri A, Rios E, Reuter J, Lee CS, Mah A, et al. Genomic analysis of mycosis fungoides and Sézary syndrome identifies recurrent alterations in TNFR2. Nat Genet. 2015;47:1056-60.

9. Kiel MJ, Sahasrabuddhe AA, Rolland DCM, Velusamy T, Chung $\mathrm{F}$, Schaller M, et al. Genomic analyses reveal recurrent mutations in epigenetic modifiers and the JAK-STAT pathway in Sézary syndrome. Nat Commun. 2015;6:8470.

10. da Silva Almeida AC, Abate F, Khiabanian H, Martinez-Escala E, Guitart J, Tensen CP, et al. The mutational landscape of cutaneous $\mathrm{T}$ cell lymphoma and Sézary syndrome. Nat Genet. 2015;47:1465-70.

11. Wang L, Ni X, Covington KR, Yang BY, Shiu J, Zhang X, et al. Genomic profiling of Sézary syndrome identifies alterations of key $\mathrm{T}$ cell signaling and differentiation genes. Nat Genet. 2015;47:1426-34.

12. Iżykowska K, Przybylski GK, Gand C, Braun FC, Grabarczyk P, Kuss AW, et al. Genetic rearrangements result in altered gene expression and novel fusion transcripts in Sézary syndrome. Oncotarget. 2017;8:39627-39.

13. Wilcox RA. Cutaneous T-cell lymphoma: 2017 update on diagnosis, risk-stratification, and management. Am J Hematol. 2017;92:1085-102.

14. Yamanaka K, Clark R, Rich B, Dowgiert R, Hirahara K, Hurwitz $\mathrm{D}$, et al. Skin-derived interleukin-7 contributes to the proliferation of lymphocytes in cutaneous T-cell lymphoma. Blood. 2006;107:2440-5.

15. Berger CL, Hanlon D, Kanada D, Dhodapkar M, Lombillo V, Wang N, et al. The growth of cutaneous T-cell lymphoma is stimulated by immature dendritic cells. Blood. 2002;99:2929-39.

16. Wilcox RA, Wada DA, Ziesmer SC, Elsawa SF, Comfere NI, Dietz AB, et al. Monocytes promote tumor cell survival in T-cell lymphoproliferative disorders and are impaired in their ability to differentiate into mature dendritic cells. Blood. 2009;114:2936-44.

17. Wu X, Schulte BC, Zhou Y, Haribhai D, Mackinnon AC, Plaza JA, et al. Depletion of M2-like tumor-associated macrophages delays cutaneous T-cell lymphoma development in vivo. J Invest Dermatol. 2014;134:2814-22.

18. Rabenhorst A, Schlaak M, Heukamp LC, Förster A, Theurich S, von Bergwelt-Baildon $\mathrm{M}$, et al. Mast cells play a protumorigenic role in primary cutaneous lymphoma. Blood. 2012;120:2042-54.

19. Tesio M, Trinquand A, Macintyre E, Asnafi V. Oncogenic PTEN functions and models in T-cell malignancies. Oncogene. 2016;35:3887-96.

20. Cristofoletti C, Picchio MC, Lazzeri C, Tocco V, Pagani E, Bresin A, et al. Comprehensive analysis of PTEN status in Sezary syndrome. Blood. 2013;122:3511-20.

21. Marzec M, Liu X, Kasprzycka M, Witkiewicz A, Raghunath PN, El-Salem M, et al. IL-2- and IL-15-induced activation of the rapamycin-sensitive mTORC1 pathway in malignant CD4+ T lymphocytes. Blood. 2008;111:2181-9.

22. Kremer M, Sliva K, Klemke C-D, Schnierle BS. Cutaneous T-cell lymphoma cells are sensitive to rapamycin. Exp Dermatol. 2010;19:800-5.

23. Narducci MG, Scala E, Bresin A, Caprini E, Picchio MC, Remotti $\mathrm{D}$, et al. Skin homing of Sézary cells involves SDF-1-CXCR4 signaling and down-regulation of CD26/dipeptidylpeptidase IV. Blood. 2006;107:1108-15.
24. Sarbassov DD, Guertin DA, Ali SM, Sabatini DM. Phosphorylation and Regulation of Akt/PKB by the Rictor-mTOR Complex. Science. 2005;307:1098-101.

25. Copp J, Manning G, Hunter T. TORC-specific phosphorylation of mammalian target of rapamycin (mTOR): phospho-Ser2481 is a marker for intact mTOR signaling complex 2. Cancer Res. 2009;69:1821-7.

26. Soliman GA, Acosta-Jaquez HA, Dunlop EA, Ekim B, Maj NE, Tee AR, et al. mTOR Ser-2481 Autophosphorylation Monitors mTORC-specific Catalytic Activity and Clarifies Rapamycin Mechanism of Action. J Biol Chem. 2010;285:7866-79.

27. Pollizzi KN, Powell JD. Regulation of T cells by mTOR: the known knowns and the known unknowns. Trends Immunol. 2015;36:13-20.

28. Hu SC-S, Lin C-L, Hong C-H, Yu H-S, Chen G-S, Lee C-H. CCR7 expression correlates with subcutaneous involvement in mycosis fungoides skin lesions and promotes migration of mycosis fungoides cells (MyLa) through mTOR activation. J Dermatol Sci. 2014;74:31-8.

29. Ieranò C, Santagata S, Napolitano M, Guardia F, Grimaldi A, Antignani E, et al. CXCR4 and CXCR7 transduce through mTOR in human renal cancer cells. Cell Death Dis. 2014;5:e1310.

30. Munk R, Ghosh P, Ghosh MC, Saito T, Xu M, Carter A, et al. Involvement of mTOR in CXCL12 mediated T cell signaling and migration. PLoS ONE. 2011;6:e24667.

31. Galloway DA, Laimins LA, Division B, Hutchinson F. HHS Public Access. 2016;7:87-92.

32. Ma XM, Blenis J. Molecular mechanisms of mTOR-mediated translational control. Nat Rev Mol Cell Biol. 2009;10:307-18.

33. Pons-Tostivint E, Thibault B, Guillermet-Guibert J. Targeting PI3K Signaling in Combination Cancer Therapy. Trends Cancer. 2017;3:454-69.

34. Lizcano JM, Göransson O, Toth R, Deak M, Morrice NA, Boudeau $\mathrm{J}$, et al. LKB1 is a master kinase that activates 13 kinases of the AMPK subfamily, including MARK/PAR-1. EMBO J. 2004;23:833-43.

35. Heckman-Stoddard BM, Gandini S, Puntoni M, Dunn BK, DeCensi A, Szabo E. Repurposing old drugs to chemoprevention: the case of metformin. Semin Oncol. 2016;43:123-33.

36. Kalender A, Selvaraj A, Kim SY, Gulati P, Brûlé S, Viollet B, et al. Metformin, independent of AMPK, inhibits mTORC1 in a rag GTPase-dependent manner. Cell Metab. 2010; 11:390-401.

37. Picchio MC, Scala E, Pomponi D, Caprini E, Frontani M, Angelucci I, et al. CXCL13 is highly produced by Sézary cells and enhances their migratory ability via a synergistic mechanism involving CCL19 and CCL21 chemokines. Cancer Res. 2008;68:7137-46.

38. Cerezo M, Tichet M, Abbe P, Ohanna M, Lehraiki A, Rouaud F, et al. Metformin blocks melanoma invasion and metastasis development in AMPK/p53-dependent manner. Mol Cancer Ther. 2013;12:1605-15.

39. Sokolowska-Wojdylo M, Wenzel J, Gaffal E, Lenz J, Speuser P, Erdmann S, et al. Circulating clonal CLA + and CD4+ T cells in Sezary syndrome express the skin-homing chemokine receptors CCR4 and CCR10 as well as the lymph node-homing chemokine receptor CCR7. Br J Dermatol. 2005;152:258-64.

40. Hashimoto I, Koizumi K, Tatematsu M, Minami T, Cho S, Takeno N, et al. Blocking on the CXCR4/mTOR signalling pathway induces the anti-metastatic properties and autophagic cell death in peritoneal disseminated gastric cancer cells. Eur J Cancer. 2008;44:1022-9.

41. Döbbeling U, Dummer R, Laine E, Potoczna N, Qin JZ, Burg G. Interleukin-15 is an autocrine/paracrine viability factor for cutaneous T-cell lymphoma cells. Blood. 1998;92:252-8. 
42. Bunn PA, Edelson R, Ford SS, Shackney SE. Patterns of cell proliferation and cell migration in the Sézary syndrome. Blood. 1981;57:452-63.

43. Gerdes J, Dallenbach F, Lennert K, Lemke H, Stein H. Growth fractions in malignant non-Hodgkin's lymphomas (NHL) as determined in situ with the monoclonal antibody Ki-67. Hematol Oncol.1984; 2: 365-71.

44. Borsig L, Wolf MJ, Roblek M, Lorentzen A, Heikenwalder M. Inflammatory chemokines and metastasis-tracing the accessory. Oncogene. 2014;33:3217-24.

45. Fujii K, Karpova MB, Asagoe K, Georgiev O, Dummer R, Urosevic-Maiwald M. Versican upregulation in Sézary cells alters growth, motility and resistance to chemotherapy. Leukemia. 2015;29:2024-32.

46. Hsieh AC, Costa M, Zollo O, Davis C, Feldman ME, Testa JR, et al. Genetic dissection of the oncogenic mTOR pathway reveals druggable addiction to translational control via 4EBP-eIF4E. Cancer Cell. 2010;17:249-61.

47. Nanki T, Lipsky PE. T Cell Activation + Is a Costimulator for CD4 Cutting Edge: Stromal Cell-Derived Factor-1. J Immunol Ref. 2018;164:5010-4.

48. Gollmer K, Asperti-Boursin F, Tanaka Y, Okkenhaug K, Vanhaesebroeck B, Peterson JR, et al. CCL21 mediates CD4+ T-cell costimulation via a DOCK2/Rac-dependent pathway. Blood. 2009;114:580-8.

49. Roelens M, Delord M, Ram-Wolff C, Marie-Cardine A, Alberdi A, Maki G, et al. Circulating and skin-derived Sézary cells: clonal but with phenotypic plasticity. Blood. 2017;130:1468-71.

50. Elenitoba-Johnson KSJ, Wilcox R. A new molecular paradigm in mycosis fungoides and Sézary syndrome. Semin Diagn Pathol. 2017;34:15-21.
51. Kohnken R, Fabbro S, Hastings J, Porcu P, Mishra A. Sézary Syndrome: Clinical and Biological Aspects. Curr Hematol Malig Rep. 2016;11:468-79.

52. Salmena L, Carracedo A, Pandolfi PP. Tenets of PTEN tumor suppression. Cell. 2008;133:403-14.

53. Zeng $\mathrm{H}$, Chi H. mTOR and lymphocyte metabolism. Curr Opin Immunol. 2013;25:347-55.

54. Kittipongdaja W, Wu X, Garner J, Liu X, Komas SM, Hwang ST, et al. Rapamycin Suppresses Tumor Growth and Alters the Metabolic Phenotype in T-Cell Lymphoma. J Invest Dermatol. 2015;135:2301-8.

55. Geskin LJ, Viragova S, Stolz DB, Fuschiotti P. Interleukin-13 is overexpressed in cutaneous T-cell lymphoma cells and regulates their proliferation. Blood. 2015;125:2798-805.

56. Wang T, Lu Y, Polk A, Chowdhury P, Zamalloa CM, Fujiwara H, et al. T-cell receptor signaling activates an ITK/NF- $\mathrm{kB} / \mathrm{GATA}-3$ axis in T-cell lymphomas facilitating resistance to chemotherapy. Clin Cancer Res. 2017;23:2506-15.

57. Witzig TE, Reeder C, Han JJ, LaPlant B, Stenson M, Tun HW, et al. The mTORC1 inhibitor everolimus has antitumor activity in vitro and produces tumor responses in patients with relapsed Tcell lymphoma. Blood. 2015;126:328-35.

58. Chiarini F, Grimaldi C, Ricci F, Tazzari PL, Evangelisti C. Activity of the novel dual phosphatidylinositol 3-kinase / mammalian target of rapamycin inhibitor NVP-BEZ235 against T-cell acute lymphoblastic leukemia activity of the novel dual phosphatidylinositol 3-kinase / mammalian target of rapamycin inhibitor NV. Cancer Res. 2010;70:8097-107. 